\title{
JELLYFISH STINGS: COMPLICATIONS AND MANAGEMENT
}

\section{By}

TOSSON A. MORSY ${ }^{1^{*}}$, NAHLA M. SHOUKRY ${ }^{2 * *}$ and MAHMOUD A. FOUAD ${ }^{3^{* * *}}$

Department of Parasitology, Faculty of Medicine, Ain Shams University, Cairo $11566^{1}$

Department of Zoology, Faculty of Science, Suez University, Suez ${ }^{2}$, Egypt, and

Department of Medical Parasitology and Microbiology, Faculty of Medicine, King

Abdulaziz University, Jeddah ${ }^{3}$, Saudi Arabia (Correspondence: *tossonmorsy@

med.asu.edu.eg or morsyegypt2014@gmail.com, orcid.org/0000-0003-2799-2049,

"nahla.m.shoukry@gmail.com \& ${ }^{* * *}$ mahmoudfouad2002@yahoo.com)

\section{Abstract}

Jellyfish and sea jellies are the informal common names given to the medusa-phase of certain gelatinous members of subphylum Medusozoa, the majority of phylum Cnidaria. Jellyfish are mainly free-swimming marine animals with umbrella-shaped bells and trailing tentacles, although a few are not mobile, being anchored to the seabed by stalks. The bell can pulsate to give propulsion and highly efficient locomotion. Tentacles are armed with stinging cells and may be used to capture prey and defend against predators. Jellyfish have a complex life cycle; the medusa is normally the sexual phase, the planula larva can disperse widely and is followed by a sedentary polyp phase.

Jellyfish are found worldwide, from surface waters to the deep sea. Scyphozoans ("true jellyfish") are exclusively marine, but some hydrozoans with a similar appearance live in freshwater. Large, often colorful, jellyfish are common in coastal zones worldwide. The medusae of most species are fast growing, mature within a few months and die soon after breeding, but the polyp stage, attached to the seabed, may be much more long-lived. Jellyfish have been in existence for at least 500 million years, and possibly 700 million years or more, making them the oldest multiorgan animal group. They are eaten by humans in certain cultures, being considered a delicacy in some Asian countries, where species in the Rhizostomae order are pressed and salted to remove excess water. They are also used in research, where the green fluorescent protein, used by some species to cause bioluminescence, has been adapted as a fluorescent marker for genes inserted into other cells or organisms. Stinging cells used by jellyfish to subdue their prey can also injure them. Many thousands of swimmers are stung every year, with effects ranging from mild discomfort to serious injury or even death; small box jellyfish are responsible for many deaths.

Key words: Jellyfish, Zoonotic importance, Management, Recommendation, Review

\section{Introduction}

Jellyfish cause most marine envenomation in the United States and worldwide. There are more than 100 species of jellyfish, and the severity and treatment of their stings vary widely, depending on the type of jellyfish, the size of the sting, and the individual patient. Jellyfish are members of the phylum Cnidaria, as are sea anemones. Jellyfish are invertebrates that float in salt and brackish water. They have a central bell and lengthy tentacles that disconnect easily and consume fish, crustaceans, and mollusks by injecting venomous capsules called nematocysts into their prey. The nematocysts are clustered along the jellyfish's tentacles and discharge rapidly on contact. The stinging mechanism can be triggered by the lightest touch and can release toxin faster than a gun releases a bullet. Physalia sp. (Portuguese Man-of-war, or bluebottle jellyfish), of the phylum Cnidaria but, are not true jellyfish, they were given as well (Balhara and Stolbach, 2014).

Jellyfish nematocysts inject a mixture of proteinaceous toxins through hollow, barbed tubes into their victims' skin at an approximate force of two to five pounds per square inch (Burnett and Calton, 1987). The venom enters the dermis and general circulation and can cause both skin and systemic symptoms in affected patients. Jellyfish do not actively seek out humans, difficult to see and most injuries occur when humans blunder into their tentacles (Dong et al, 2010). Long-term effects of climate change \& overfishing on jellyfish populations are uncertain, they nu- 
mbers increased in some ecosystems, but decreased in others (Mills, 2001).

\section{Review and General Discussion}

Epidemiology Jellyfish stings are common in warm and cold coastal waters, although exact prevalence rates are unknown. Burnett (1992) reported 500,000 annual envenomations in the Chesapeake Bay and 60,000 to 200,000 annually along the Florida coast. Kokelj et al. (1999) estimated 5000 stings in the thermal baths of Grado on the Gulf of Trieste in summer 1997 Vimpani et al. (1988) in tropical northern Australia, stings from the major box jellyfish Chironex fleckeri resulted in about one pediatric death in a remote area every two to three years. O'Reilly et al. (2001) reported many more nonfatal and less severe cases mainly in the Northern Territory Huynh et al. (2003) reported few hundred cases of Irukandji syndrome from other box jellyfish, including Carukia barnesi, occurred annually in the same region. Two known deaths from Portuguese man-ofwar stings along the Atlantic coast of the United States were reported in 1988 (Macrokanis et al, 2004). Jellyfish outbreaks have provoked concern about their potential harm to man and stimulated researches in the past two decades (Graham et al, 2014). Through process of carbon sequestration, they provide regulating services (Doyle et al, 2014), contribute nutrients to support primary production (West et al, 2009) and organic matter that stimulates microbes to be hostpromoted, anthropogenic pressure, and pl-ay a role in structuring the associated anthropogenic pollution (Kos Kramar et al, 2019).

In the Eastern Mediterranean Region, Gusmani et al. (1997) in Italy reported that thetropical jellyfish, Rhopilema nomadica (Scyphozoa, Rhizostomeae) with its bane painful stings bathers and fishermen from Egypt to Turkey. They reported hemolytic activity $\&$ alpha-chymotrypsin-like serine protease activity in its nematocysts venom, and the already described phospholipase A2 activity. Thus, prevalence of the jellyfish swarms and the severity of clinical manifestations due to their risky envenomations must be considered as a health hazard in the Mediterranean Sea (Glatstein et al, 2018). Moreover, the Mediterranean Sea is heavily affected by jellyfish bloom phenomena, due to the scyphozoans, such as the Rhizostoma pulmo. They have few natural predators, and their bodies represented an organic-rich substr-ate that can support rapid bacterial growth with great impact on the structure of marine food webs (Angilè et al, 2020).

Types of jellyfish: While many types of jellyfish are relatively harmless to humans, others can cause severe pain and are more likely to cause a systemic reaction. These jellyfish cause more-serious problems in people: 1- Box jellyfish: Box jellyfish can cause intense pain. Life-threatening reactions, although rare, but are commonest with this type. The more dangerous species of box jellyfish are in the warm waters of the Pacific and Indian oceans. 2- Portuguese man-ofwar: Also called bluebottle jellyfish, Portuguese man-of-war jellyfish live mostly in the warmer seas. This type has a blue or purplish gas-filled bubble that keeps it afloat on the water and acts as a sail. 3- Sea nettle: Common in both warm and cool seawaters, sea nettles live along the northeast coast of the United States and are abundant in the Chesapeake Bay. 4- Lion's mane jellyfish: These are the world's largest jellyfish, with a body diameter of more than 3 feet $(1$ meter), and most common in cooler, northern regions of the Pacific and Atlantic oceans.

The clinical presentation of a patient with jellyfish stings varied according to the type of jellyfish, individual characteristics of the patient, duration of exposure and amount of skin exposed, and type of treatment administered at the time of exposure. The stinging mechanism can be triggered by the lightest touch and can release toxin faster than a gun releases a bullet. Patients may not see the tentacle, but they usually experience immediate pain at the time of the sting. Linear red, urticarial lesions typically develop a few minutes later, although sometimes these lesions 
do not appear for several hours, which often burn intensely and may itch and throb. The pain can radiate up a limb to the torso (Fox, 2000).

Tentacle prints may be seen on skin examination, and less commonly vesiculation and ecchymosis (Kaufman, 1992). Skin necrosis can occur with more severe stings, such as with $C$. fleckeri. The initial erythematous lesions are usually localized to the sting area. In some cases eruptions, such as papular urticarial reactions, can recur days later. This was reported in about $60 \%$ of $C$. fleckeri stings, and the lesions usually resolved within 10 days, but may persist for weeks (Kain, 1999).

Ocular jellyfish stings can initially cause burning pain, photophobia, epithelial keratitis, corneal stromal edema, endothelial cell swelling, and anterior chamber inflammation, which usually resolve within 48 hours (Glasser et al, 1992). Several patients have been described who developed severe iritis and increased intraocular pressure after corneal stings, including one who developed chronic unilateral glaucoma four years after a jellyfish sting in Chesapeake Bay (FillingKatz, 1984).

There were case reports of mononeuritis multiplex and Guillain-Barré syndrome, apparently related to jellyfish stings (Pang and Schwartz, 1993). An acute myocardial infarction was described in a 45-year-old man with normal coronary arteries who was stung by an undetermined species of jellyfish; he was stung once on his forearm four hours before the onset of symptoms of myocardial ischemia (Salam et al, 2003).

Venom composition: Venom consists of toxins and multiple proteins, which are specifically isoforms of the cnidarian proteins. By using toxin-specific stains and phosphoprotein/glycoprotein-specific stains, the glycosylation is a common toxin in venom. Glycosylation is reaction with a carbohydrate attached to a hydroxyl. Glycosylation is also enzymatic process that attaches glycans to proteins, lipids, or other organic mol- ecules. Toxins include CfTX-1 \& CfTX-2, as well as two additional toxins, CfTX-A \& CfTX-B, and a third putative toxin, CfTX-Bt (Jouiaei et al, 2015).

Irukandji syndrome: Irukandji syndrome typically involves a mild to moderately painful local sting that is followed 20-40 minutes later by the onset of severe generalized back, chest, and abdominal pain, gastro-intestinal symptoms, sweating, agitation, hypertension and tachycardia. Patients developed myocardial injury and pulmonary edema in about 6 to 18 hours after sting (Little et al, 2003).

Carukia barnesi, found in Northern Australian waters, was the first jellyfish identified to cause Irukandji syndrome, it is a creature with a tiny bell (often $2 \mathrm{~cm}$ in diameter) and long tentacles. Other Australian jellyfish may cause some cases of Irukandji syndrome (Little et al, 2006). There were case reports of an Irukandji-like syndrome occurring in locations outside the habitat of C. barnesi, including off Hawaii and the southern coast of Florida (Grady and Burnett, 2003)

Severe stings: Major box jellyfish (Chironex fleckeri) stings have caused more than 70 known deaths in Australia (Currie and Jacups, 2005). Multiple tentacles arising from the four corners of this large jellyfish may stretch to 2 meters, lined with nematocysts contained the venom producing cardiotoxic, neurotoxic, dermonecrotic, and hemolytic effects in in vitro experiments (Ramasamy et al, 2003). But, most Australian box jellyfish stings are of little consequence (Ramasamy et al, 2004), with large tentacular contact patients can experience rapid onset of cardiac arrest within minutes of the sting. Delayed hypersensitivity reactions occurred 7-14 days after the sting and papular urticaria at the initial site of contact were common; 11 of 19 patients suffered from C. fleckeri stings developed the delayed hypersensitivity (Bailey et al, 2003).

Deaths were rarely reported with the Atlantic Portuguese man-of-war; or Man-of-war (Physalia sp., or bluebottle jellyfish) caused numerous stings worldwide. The patients 
may go into the cardiovascular or respiratory arrest or drown from paralysis of a limb and there was a fatal envenomation of a child by Chiropsalmus quadrumanus (Bengtson et al, 1991).

Seabather's eruption: Seabather's eruption is an itchy dermatitis described in Florida, the Caribbean, Bermuda, and Long Island, New York. It occurred on parts of skin that are covered by a swim-suit and is believed to be caused by jellyfish and sea anemone larvae, which become trapped and pressed between the outfit and the person's skin. Skin reaction recurred when the outfit was worn again, due to nematocysts persistence in the suit. Malaise, fever, and gastrointestinal symptoms can also occur in a minority of such patients (Freudenthal and Joseph, 1993).

Jellyfish's collagen: Collagen has an abundance of proteins and minerals. Analysis of amino acid composition of mesogloea hydrolysate showed the characteristic hydroxylproline and hydroxylysine. Jellyfish protein made almost entirely of collagen (80 to $90 \%$ ), are rich in hydroxylysine and its glycosides (Brinckmann, 2005)

In contrast to jellyfish skin collagen, the mesogloea collagen was found to lack disulfide linkages. Collagen is generally un-ique to the organism, or even the type of tissue, from which it is derived. A detailed description of the structure and the biological functions of the various different types of naturally occurring collagens can be found in Type II collagen from jellyfish has been used to treat rheumatoid arthritis (RA), specifically, type II collagen induced oral tolerance in a subject suffering from RA. All of that after venom removing in process called "milking" which is process of extraction deadly venom to provide a sufficient venom supply for future research about developing life-saving anti-venom against the sting of the deadly jellyfish (Ding et al, 2010).

Addad et al. (2011) reported that fibrillary collagens are the more abundant extra-cellular proteins form a metazoan-specific fami- ly, and are highly conserved from sponge to human. The structural and physiological characters have been successfully used in the human food, cosmetic, and pharmaceutical industries. So, the increase of jellyfish has led authors to consider this marine animal as a natural product for food and medicine. They concluded that the broad harmlessness of jellyfish collagens and their biological effect on human cells that are similar to that of mammalian type I collagen. Given the bioavailability of jellyfish collagen and its biological properties, this marine material proved to a good candidate for replacing bovine or human collagens in selected biomedical applications.

Diagnosis: In most cases, diagnosis of a jellyfish sting is done clinically or is simply recognized by the patient who has been stung in waters known to harbor jellyfish. Clues to the type of jellyfish include the geographic area where the sting occurred, the distance from the shore, and the pattern of the tentacle print on the skin.

A definitive diagnosis is sometimes needed when the clinical picture is unclear or for research purposes. When such a diagnosis is required, nematocysts can be examined under a microscope and compared to known nematocysts from various jellyfish. Nematocysts can generally be easily identified for common jellyfish. For uncommon jellyfish or in areas where stings are uncommon, the microscopic examination should be performed by an expert who has access to the cnidomes of medically significant jellyfish.

Nematocyst of Chironex fleckeri retrieval from skin by a simple sticky tape method was at least as good as scraping with a scalpel blade and also retrieved by sticky tape method (Currie and Wood, 1995). The skin scraping was the better method for retrieving nematocysts but was slightly painful; but the only method used to collect nematocysts from bell stings (e.g., C. barnesi) and was then put in 1 to $4 \%$ formalin (Loten et al, 2006). Recovery of the C. fleckeri nematocysts from human skin can be performed 
with sticky tape, but Physalia species, flush the affected area with sea water to remove any of the adherent tentacles (Dalefield, 2017).

Prevention: Generally underwater tentacles of jellyfish can be long and difficult to see and so pose a hazard to all ocean swimmers. It is important to avoid touching tentacles along the shore, since they often contain nematocysts that can discharge and sting. In regions where box jellyfish stings occurred, not entering the water during jellyfish season was the most effective prevention means (Auerbach, 1997).

Stinger nets and stinger suits exist that can provide a mechanical barrier to some jellyfish; however, stinger nets do not appear to protect against the small jellyfish that cause Irukandji syndrome. The clothing that created a barrier, such as wet suits or rash guards worn by surfers, may protect against tentacle stings. While it seems reason-able that these would offer at least some protection, we know of no well-performed trials demonstrating efficacy (Kimball et al, 2004).

Topical: A sting inhibitor called "safe sea lotion" is marketed for protection against jellyfish stings. Its contents reportedly mimic the mucous coating that clown fish use to inhibit stings by sea anemones. In a blinded experimental study, 24 volunteers had their inhibitor applied to one forearm and a sunscreen placebo applied to the second forearm and then each forearm was exposed to a jellyfish tentacle; 12 subjects were exposed to Chrysaora fuscescens (a type of sea nettle) and 12 were exposed to Chiropsalmus quadrumanus (a box jellyfish type). The inhibitor significantly decreased the stings frequency as seen both by subjective pain and objective erythema (Boulware, 2006).

Treatment: Treatment included the firstaid care and medical treatment, depending on the type of jellyfish, the severity of the sting and victim reaction to it. It was important to remove jellyfish tentacles promptly, since nematocysts may continue to fire toxins into the attached skin. The tentacles can be easily brushed off using a plastic object (such as a credit card) and a substance such as shaving cream. The affected limb should not be immersed in cool fresh water, since the osmotic pressure of fresh water may cause nematocysts to fire. Seawater can be used to wash tentacles off affected areas. But, vigorous rubbing can stimulate the nematocysts, which must be avoided (Nochetto and Bird, 2012).

In vitro studies, acetic acid (householdvinegar) inhibited the nematocysts discharge from Australian box jellyfish (Hartwick et al, 1980). Acetic acid was best used in the cases with the risky life-threatening effects, such as with box jellyfish stings. Although it prevented further discharge of nematocysts from at least some species of jellyfish, it did not offer any symptomatic relief or treatment of the established envenomation effects (Burnett et al, 1983). The vinegar provoked nematocyst discharge from Physalia sp. (Portuguese man-of-war), but others found that it inhibited discharge (Fenner et al, 1993). The Australian Resuscitation Council's 2005 guidelines recommended immediate application of acetic acid for box jellyfish stings (Jacobs and Morley, 2006). Although acetic acid was tested on Hawaiian box jellyfish (C. alata), yet it was commonly used for the Hawaiian box jellyfish stings (Thomas et al, 2001).

Heat and cold: Studies regarding the application of heat or cold have varied, however heat appears to be an effective treatment for at least some jellyfish stings. Heat may be able to alter the protein structure of jellyfish toxins (Carrette et al, 2002).

One well-performed study applied Hawaiian box jellyfish (Carybdea alata) tentacles to both forearms of healthy adult volunteers and then randomly treated one forearm with hot $\left(40-41^{\circ} \mathrm{C}\right)$ fresh water immersion; the other forearm was randomly treated with either household vinegar (5\% acetic acid) or papain meat tenderizer (Adolph's meat tenderizer) and water in a 4:1 ratio (Nomura et $a l, 2002)$. The hot water treatment was sig- 
nificantly superior in relieving pain to either of the other therapies. A trial of hot and cold packs for C. alata found a trend toward pain relief with hot packs and no relief with cold packs, but it was not clear that application of a hot pack would achieve the same degree of warming as hot water immersion (Thomas et al, 2001).

An uncontrolled retrospective case series from Australia had suggested that cold packs provide effective analgesia for Cyanea (hair jellyfish), Tamoya (fire jellyfish), Physalia (Portuguese Man-of-war, or bluebottle jellyfish), and small box jellyfish stings, but not for large box jellyfish stings, or treating Physalia stings with ice packs (Exton et al, 1989). However, a randomized trial in Florida, where Physalia sp. are common, found that patients whose affected limbs were soaked in hot water $\left(43^{\circ} \mathrm{C}\right)$ after nematocyst removal experienced faster pain relief than patients who applied cold packs to the affected area (Lopez et al, 2000). Also, a randomized trial in 96 Australian patients found hot water immersion $\left(45^{\circ} \mathrm{C}\right)$ more effective than ice packs for Physalia sp. (Atkinson et $a l$, 2006). After 20 minutes of therapy, significantly more patients reported clinically important pain relief with hot water (87 vs. $33 \%$ ). These may somewhat overestimate the relative benefits of hot water because the trial was stopped early based on an interim analysis, and be-cause pain at baseline was greater in hot water treatment group. The authors noted that hot water immersion at higher temperatures or for longer than an hour increased the risk of burns. These results showed that hot water immersion is effective for at least some jellyfish stings. It is not necessarily appropriate to extrapolate from studies in one species of jellyfish to other species. In particular, studies have not evaluated the effect of hot water immersion on Australian box jellyfish (C. fleckeri) stings. But, at least for stings due to $C$. alata (Hawaiian box jellyfish) and Physalia sp. (Portuguese Man-of-war, also called bluebottle jellyfish), it was recommended to treat with hot water after tentacle removal. The water temperature must be 40 to $45^{\circ} \mathrm{C}$ and should be applied by immersion of a limb or by hot shower for approximately 20 minutes. If a thermometer is not available, use the hottest water temperature that is tolerated by the patient on an unaffected limb; adults must test the water temperature for the young children and babies.

Topical therapies: There are many popular remedies for immediate topical treatment of stings, but evidence regarding their effectiveness varies.

Papain meat tenderizer: Adolph's meat tenderizer contained papain; a proteolytic enzyme that theoretically cleaves nematocyst toxins was advocated for the jellyfish stings treatment (Loder, 1973).

A well-performed study that compared hot water immersion with papain meat tenderizer found hot water immersion to be superior in relieving pain. A trial that compared treatment with papain meat tenderizer, StingAid (a commercial product consisting of water, detergent, and aluminum sulfate), and the sea water as a control in patients with $C$. alata stings who had already been treated with vinegar found no benefit to either therapy: methodologic issues in this study could have resulted in a real effect being missed.

Other in-vitro studies of methylated spirits, ethanol, and human urine (a popular remedy) showed a marked increase in release of nematocyst toxin of Australian box jellyfish. Slurry of baking soda appears to inhibit nematocyst discharge from the sea nettle (Chrysaora quinquecirrha). Although the immobilization of the affected body part and application of a pressure bandage after tentacle removal has been proposed for box jellyfish s tings, yet it was dangerous and must not be performed (Beadnell et al, 1992).

Delayed hypersensitivity: Delayed hypersensitivity reactions are common after Australian box jellyfish (C. fleckeri) stings. Patients not spontaneously improved must use the oral antihistamines and topical corticosteroids (Raupp et al, 1996). 
Systemic symptoms: Such as respiratory distress, should be treated supportively. The cardiac toxicity is characterized by a fast and irregular cardiac rhythm and conduction block. Death may ensue within minutes due to cardiotoxic and neurotoxic agents in the venom that can produce ventricular arrhythmias, cardiac arrest, and respiratory failure, respectively. In 12 serious cases (Martin and Audley, 1990), pulmonary edema was a main feature after an initial phase of mild skin pain followed 30min after sting by considerable muscle pain and cramps, tachycardia and hypertension. At a mean time of 14 hr (range 1.5 18hr) after the sting pulmonary edema was evident radiologically and in so-me cases was associated with hypokinetic cardiac dysfunction, reduced cardiac output and raised serum cardiac enzymes. Hypertension (Ramasamy et al, 2005), and hypertension due to catecholamine release (Pereria et al, 2007) were reported in animal models of $C$. barnesi envenomation. But, the catecholamine excess has yet confirmed in human cases. The antivenom is available for severe Australian box jellyfish (C. fleckeri) stings prepared from the sheep serum, was indicated for cardiopulmonary instability and cardiac arrest (Cegolon et al, 2013). It must be given intravenously soon after sting, since most deaths occur within five to twenty minutes (Currie, 2003).

Steps to avoid: These actions are unhelpful or unproved: a- Scraping out stingers, bRinsing with seawater, c- Rinsing with human urine, d- Rinsing with fresh water, eApplying meat tenderizer, f- Applying ethanol or ammonia, g- Rubbing with a towel, or $\mathrm{h}$ - Applying pressure bandages.

There were some concerns regarding the efficacy of the anti-venom. A study examined this result both in vitro and with animals (Winter et al, 2009), in-vitro, antivenom banded all major toxins (on Western blot). In a rat model, mixtures of venom-antivenom did not cause cardiovascular collapse, while this occurs rapidly with venom alone. However, when the antivenom was adminis- tered to the rats, rather than preincubated with venom, it was ineffective in preventing cardiovascular collapse even when administered intravenously prior to giving the venom. It showed that although the antivenom was biologically active, it was unlikely to be able to work quickly enough clinically to prevent the rapid effects of venom on the cardiovascular system. It is unlikely that any clinical trial performed with the antivenom. As such, the administration of the antivenom confined to early use in patients with cardiogenic shock or cardiac arrest. When used, administer one vial $(20,000$ units) intravenously over five to ten minutes as the initial dose; dosing may be repeated up to a maximum of six vials for patients who remain in the cardiogenic shock or cardiac arrest. The same dose is used for adults and children.

Pretreatment with the magnesium sulfate improved the efficacy of antivenom although it had no benefit when administered without antivenom.

In the absence of better evidence, we suggest that Australian box jellyfish victims with severe cardiovascular effects that have responded poorly to advanced life support and antivenom be treated with an infusion of magnesium sulfate. An appropriate dose was $0.2 \mathrm{mmol} / \mathrm{kg}(0.05 \mathrm{gm} / \mathrm{kg})$ to a maximum of $10 \mathrm{mmol}(2.5 \mathrm{gm})$, given as an intravenous bolus over 5 to 15 minutes.

A case report and a small case series suggested benefits with magnesium administration for the Irukandji syndrome (Corkeron, 2003). However, the large amounts of magnesium sometimes required can lead to adverse effects including neurotoxicity. However, more research is required before one can recommend the routine use of magnesium for Irukandji syndrome.

Seabather's eruption: It is characterized by the intensely itchy erythematous papules observed mainly in the region covered by swimwear. Dermatitis caused by of juvenile thimble jellyfish injection (Linuche unguiculata) nematocysts into human skin (Calder, 2009). The condition did not occur immedi- 
ately, but after the showering or the skin was dried, killing jellyfish larvae which react by discharging their stinging cells and usually treated with topical antihistamines and corticosteroids (Rossetto and Proença, 2012).

\section{Summary and Recommendations}

The prevalence of the jellyfish swarms and the severity of clinical manifestations because of their envenomations suggested that it must be considered as a health hazard in the Mediterranean Sea.

When conditions are favorable, jellyfish can form vast swarms. These can be responsible for damage to fishing gear by filling fishing nets, and sometimes clog cooling systems of power and desalination plants that draw their water from the sea.

The clinical presentation of a patient with jellyfish stings varies according to the type of jellyfish, individual characteristics of the patient, duration of exposure and amount of skin exposed, and type of treatment administered at the time of exposure. Patients may not see the tentacle, but they usually experience immediate pain at the time of the sting. The majority of jellyfish stings present with linear red, urticarial and/or painful lesions typically developing a few minutes later, although sometimes these lesions do not appear for several hours. Systemic symptoms can occur, and stings from C. fleckeri in particular, can occasionally be fatal.

Prevention in regions where box jellyfish stings occur, not entering the water during jellyfish season is the most effective means of prevention. Swimming in jellyfish waters, wearing clothing or suits that provide a mechanical barrier to stings are re-commended (Grade 2C). For swimmers at high risk of exposure to the jellyfish must use safe sea lotion (Grade 2B). There are limited data to make evidence-based recommendations as to manage jellyfish stings. Remove the jellyfish tentacles promptly to prevent continued release of the venom by nematocysts. They must be carefully brushed off using a plastic object (e.g. a credit card) and a substance like shaving cream. After tentacle removal, the stings due to $C$. alata (Hawaiian box jellyfish) and Ph-ysalia sp. (Portuguese manof-war or bluebottle jellyfish) must be treated with hot water (Grade 1A).

The water temperature should be 43 to 45 ${ }^{\circ} \mathrm{C}$ and should be applied by immersion of a limb or by hot shower for approximately 20 minutes. If a thermometer is not available, use the hottest water temperature that is tolerated by the patient on an unaffected limb; adults should test the water temperature for young children.

Hot water may be helpful for stings from other jellyfish as well, but not for $C$. fleckeri (Australian box jellyfish) stings. The nurse on duty must not immerse the wound in cool fresh water or vigorously rubbing the wound (Grade 1C). Soaking the wound in seawater may decrease discomfort, although there are no specific data supporting this practice, but do not treat jellyfish stings with urine or ethanol (Grade 2C). C. fleckeri (Australian box jellyfish) and $C$. alata (Hawaiian box jellyfish) stings must be treated with acetic acid (household vinegar) (Grade 2C). Antivenom is available and used for severe Australian box jellyfish stings, but must be administered quickly to be effective. The patients with early severe cardiogenic shock or cardiac arrest from the Australian box jellyfish stings must be treated with antivenom (Grade 2C). When used, give a vial (20,000 units) intravenously over five to ten minutes as the initial dose; dosing may be repeated up to a maximum of six vials for patients who remain in cardiogenic shock or cardiac arrest. The same dose is used for adults and children. The Australian box jellyfish victims with severe cardiovascular effects poorly responded to advanced life support and antivenom must be treated with an infusion of magnesium sulfate (Grade 2C). An appropriate dose was $0.2 \mathrm{mmol} / \mathrm{kg}(0.05 \mathrm{gm} / \mathrm{kg})$ to a maximum of $10 \mathrm{mmol}(2.5 \mathrm{gm})$, given as an intravenous bolus over 5 to 15 minutes. Delayed hypersensitivity from Australian box jellyfish stings can be treated with the oral anti-histamines and topical corticosteroids. 


\section{References \\ Addad, S, Exposito, J, Faye, C, Ricard-Blum,}

S, Lethias, C, 2011: Isolation, characterization and biological evaluation of jellyfish collagen for use in biomedical applications. Mar Drugs 9, 6:96783. doi: 10.3390/md9060967. Epub 2011 Jun 7.

Angilè, F, Del-Coco, L, Girelli, CR, Basso, L, Rizzo, L, et al, 2020: ${ }^{1} \mathrm{H}$ NMR metabolic profile of Scyphomedusa Rhizostoma pulmo (Scyphozoa, Cnidaria) in female gonads and somatic tissues: preliminary results. Molecules Feb 13; 25(4). pii: E806. doi: 10.3390/molecules 25040806

Atkinson, PRT, Boyle, A, Hartin, D, Mc-Auley, D, 2006: Is hot water immersion an effective treatment for marine envenomations? Emerg. Med. J. 23:503-8.

Auerbach, PS, 1997: Envenomations from jellyfish and related species. J. Emerg. Nurs. 23: 555-8.

Bailey, PM, Little, M, Jelinek, GA, 2003: Jelly -fish envenoming syndromes: Unknown toxic mechanisms and unproven therapies Med. J. Aust. 178:34-8.

Balhara, KS, Stolbach, A, 2014: Marine envenomations. Emerg. Med. Clin. North Am. 32, 1:223-43.

Beadnell, CE, Rider, TA, Williamson, JA, Fenner, PJ, 1992: Management of a major box jellyfish (Chironex fleckeri) sting: Less-ons from the first minutes and hours. Med. J. Aust. 156:655-70.

Bengtson, K, Nichols, MM, Schnadig, V, Ellis, MD, 1991: Sudden death in a child following jellyfish envenomation by Chiropsalmus quadrumanus: Case report and autopsy findings. JAMA 266:1404-9.

Boulware, DR, 2006: A randomized, controlled field trial for the prevention of jellyfish stings with a topical sting inhibitor. J. Travel Med. 13: 166-70.

Brinckmann, J, 2005: Collagens at a glance. Top. Curr. Chem. 247:1-6.

Burnett, JW, 1992: Human injuries following jellyfish stings. Md. Med. J. 41:509-12.

Burnett, JW, Calton, GJ, 1987: Jellyfish envenomation syndromes updated. Ann. Emerg. Med. 16:1000.

Burnett, JW, Rubinstein, H, Calton, GJ, 1983: First aid for jellyfish envenomation. South Med. J. 76:870-5.
Calder, D. 2009: Cubozoan and Scyphozoan jellyfishes of the Carolinian biogeographic province, southeastern USA. Toronto, ON, Canada: Royal Ontario Museum.

Carrette, TJ, Cullen, P, Little, M, et al, 2002: Temperature effects on box jellyfish venom: A possible treatment for envenomed patients? Med. J. Aust. 177:654-8.

Cegolon, L, Heymann, WC, Lange, JH, Mastrangelo, G, 2013: Jellyfish stings and their management: A review. Mar. Drugs 11, 2:523-50.

Corkeron, MA, 2003: Magnesium infusion to treat Irukandji syndrome. Med. J. Aust. 178: 411-8.

Currie, BJ, 2003: Marine antivenoms. J. Toxicol. Clin. Toxicol. 41:301-6.

Currie, BJ, Jacups, SP, 2005: Prospective study of Chironex fleckeri and other box jellyfish stings in the "Top End" of Australia's Northern Territory. Med. J. Aust. 183:631-4.

Currie, BJ, Wood, YK, 1995: Identification of Chironex fleckeri envenomation by nematocyst recovery from skin. Med. J. Aust. 162, 9:47880.

Dalefield, R, 2017: Veterinary Toxicology for Australia and New Zealand. books.google. com. eg > books

Ding, J, Su, X, Zhang, C, Li, Y, Xu, J, 2010: Extraction of collagen from jellyfish (Rhopilema esculentum) \& wound healing-promoting effect in mouse. Food Sci. 31, 24: 19-23,DOI: 10.7506 /spkx1002-6630-2010240 04.

Dong, Z, Liu, D, Keesing, JK, 2010: Jellyfish blooms in China: Dominant species, causes and consequences. Mar. Pollut. Bull. 60, 7:954-63.

Doyle, TK, Hays, GC, Harrod, C, Houghton, JDR, 2014: Ecological and Societal Benefits of Jellyfish In: Pitt K. A, Lucas CH, editors. Jellyfish Blooms. Springer; Netherlands.

Exton, DR, Fenner, PJ, Williamson, JA, 1989: Cold packs: effective topical analgesia in the treatment of painful stings by Physalia and other jellyfish. Med. J. Aust.151:625-9.

Fenner, PJ, Williamson, JA, Burnett, JW, Rifkin, J, 1993: First aid treatment of jellyfish stings in Australia: Response to a newly differentiated species. Med. J. Aust. 158:498-502.

Filling-Katz, MR, 1984: Mononeuritis multiplex following jellyfish stings. Ann. Neurol. 15:213-8.

Fox, JW, 2000: Venoms and poisons from marine organisms. In: Cecil Textbook of Medicine, $21^{\text {st }}$ Ed, Goldman (Ed.), W.B. Saunders. 
Freudenthal, AR, Joseph, PR, 1993: Seabater's eruption. N. Engl. J. Med. 329:542-6.

Glasser, DB, Noell, MJ, Burnett, JW, et al, 1992: Ocular jellyfish stings. Ophthalmology 99:1414-8.

Glatstein, M, Adir, D, Galil, B, Scolnik, D, Rimon, A, et al, 2018: Pediatric jellyfish envenomation in the Mediterranean Sea. Eur. J. Emerg. Med. 25, 6:434-9.

Grady, JD, Burnett, JW, 2003: Irukandji-like syndrome in South Florida divers. Ann. Emerg. Med. 42:763-7.

Graham, WM, Gelcich, S, Robinson, KL, Duarte, CM, Brotz, L, et al, 2014: Linking human well-being and jellyfish: Ecosystem services, impacts, and societal responses. Front. Ecol. Environ. 12, 9:515-23.

Gusmani, L, Avian, M, Galil, B, Patriarca, P, Rottini, G, 1997: Biologically active polypeptides in the venom of the jellyfish Rhopilema nomadica. Toxicon. 35, 5:637-48.

Hartwick, R, Callanan, V, Williamson, J, 1980: Disarming the box-jellyfish: nematocyst inhibition in Chironex fleckeri. Med. J. Aust. 1: 15-20.

Huynh, TT, Seymour, J, Pereira, P, et al, 2003: Severity of Irukandji syndrome and nematocyst identification from skin scrapings. Med. J. Aust. 178:38.

Jacobs, LG, Morley, PT, 2006: The Australian Resuscitation Council: new guidelines for 2006 www.resus.org.au.

Jouiaei, M, Casewell, NR, Yanagihara, AA, Nouwens, A, Cribb, BW, et al, 2015: Firing the sting: chemically induced discharge of cnidae reveals novel proteins and peptides from box jellyfish (Chironex fleckeri) venom. Toxins (Basel) 7, 3:936-50.

Kain, KC, 1999: Skin lesions in returned travelers. Med. Clin, North Am. 83:1077-80.

Kaufman, MB, 1992: Portuguese man-of-war envenomation. Pediatr. Emerg. Care 8:27-32.

Kimball, AB, Arambula, KZ, Stauffer, AR, et al, 2004: Efficacy of a jellyfish sting inhibitor in preventing jellyfish stings in normal volunteers. Wilderness Environ Med 15:102-8.

Kokelj, F, Lo Brutto, R, Boccucci, N, 1999: Epidemiological study of human injuries following jellyfish stings in the Gulf of Trieste. Contact Dermatitis 41:349-52.

Kos Kramar, M, Tinta, T, Lučić, D, Malej, A, Turk, V, 2019: Bacteria associated with moon jellyfish during bloom and post-bloom peri- ods in the Gulf of Trieste (northern Adriatic). PLoS One Jan 15;14, 1: e 0198056. doi: 10.1371 / journal.pone.0198056.

Little, M, Pereira, P, Carrette, T, Seymour, J, 2006: Jellyfish responsible for Irukandji syndrome. QJM 99:425.

Little, M, Pereira, P, Mulcahy, R, et al, 2003: Severe cardiac failure associated with presumed jellyfish sting: Irukandji syndrome? Anaesth. Intensive Care 31:642-4.

Loder, JS, 1973: Letter: Treatment of jellyfi- sh stings. JAMA 226:1228-31.

Lopez, EA, Weisman, RS, Bernstein, J, 2000: A prospective study of the acute therapy of jellyfish envenomations. J. Toxicol. Clin. Toxicol. 38:513-6.

Loten, C, Stokes, B, Worsley, D, et al, 2006: A randomized controlled trial of hot water $\left(45^{\circ} \mathrm{C}\right)$ immersion versus ice packs for pain relief in bluebottle stings. Med. J. Aust. 184: 329-33.

Macrokanis, CJ, Hall, NL, Mein, JK, 2004: Irukandji syndrome in northern Western Australia: An emerging health problem. Med. J. Aust. 181:699-702.

Martin, JC, Audley, I, 1990: Cardiac failure following irukandji envenomation. Med. J. Aust. 153:164-6.

Mills, CE, 2001: Jellyfish blooms: are populations increasing globally in response to changing ocean conditions? Hydrobiologia 451:55-9. Nochetto, M, Bird, N, 2012: First Aid for Hazardous Marine Life Injuries. Divers Alert Network.

Nomura, JT, Sato, RL, Ahern, RM, et al, 2002: A randomized paired comparison trial of cutaneous treatments for acute jellyfish (Carybdea alata) stings. Am. J. Emerg. Med. 20:624-6. O'Reilly, GM, Isbister, GK, Lawrie, PM, et al, 2001: Prospective study of jellyfish stings from tropical Australia, including the major box jellyfish Chironex fleckeri. Med. J. Aust. 175:652-6.

Pang, KA, Schwartz, MS, 1993: Guillain-Barre syndrome following jellyfish stings (Pelagia noctiluca). J. Neurol. Neurosurg. Psychiatry 56: 1133-9.

Pereira, LC, Jiménez, JA, Medeiros, C, da Costa, RM, 2007: Use and occupation of olinda littoral (ne, brazil): Guidelines for an integrated coastal management. Environ. Manag. 40:210-8. Ramasamy, S, Isbister, GK, Seymour, JE, Hodgson, WC, 2003: The in vitro effects of two chirodropid (Chironex fleckeri and Chiropsalmus sp.) venoms: Efficacy of box jellyfish 
antivenom. Toxicon 41:703-6.

Ramasamy, S, Isbister, GK, Seymour, JE, Hodgson, WC, 2004: The in vivo cardiovascular effects of box jellyfish Chironex fleckeri venom in rats: Efficacy of pre-treatment with antivenom, verapamil and magnesium sulphate. Toxicon 43:685-8.

Ramasamy, S, Isbister, GK, Seymour, JE, Hodgson, WC, 2005: Pharmacologically distinct cardiovascular effects of box jellyfish (chironex fleckeri) venom and a tentacle-only extract in rats. Toxicol. Lett. 155:219-26.

Raupp, U, Milde, P, Goerz, G, Plewig, G, Burnett, J, et al, 1996: Case report of jellyfish injury. Hautarzt. 47, 1:47-52.

Rossetto, AL, Proença, LA, 2012: Seabather's eruption: Report of case in northeast region of Brazil. Ann. Bras. Dermatol. 87, 3:472-4.

Salam, AM, Albinali, HA, Gehani, AA, Al

Suwaidi, J, 2003: Acute myocardial infarction in a professional diver after jellyfish sting. Mayo Clin. Proc. 78:1557-60.

Thomas, CS, Scott, SA, Galanis, DJ, Goto, R S, 2001: Box jellyfish (Carybdea alata) in Waikiki: The analgesic effect of sting-aid, Adolph's meat tenderizer and fresh water on their stings: a double-blinded, randomized, placebo-controlled clinical trial. Hawaii Med. J. 60:205-10.

Vimpani, G, Doudle, M, Harris, R, 1988: Child accident-mortality in the Northern Territory, 1978-1985. Med. J. Aust. 148:392-5.

West, EJ, Welsh, DT, Pitt, KA, 2009: Influence of decomposing jellyfish on the sediment oxygen demand and nutrient dynamics. Hydrobiologia 616:151-60.

Winter, KL, Isbister, GK, Jacoby, T, et al, 2009: An in vivo comparison of the efficacy of CSL box jellyfish antivenom with antibodies raised against nematocyst-derived Chironex fleckeri venom. Toxicol. Lett.187:94-8.

Explanation of figures

Fig. 1: Sea Wasp Box Jellyfish, Fig. 2: Irukandji Jellyfish, Fig. 3: Portuguese Man-of -war, Fig. 4: Lion's mane jellyfish, Fig. 5: Sea Nettle, Fig. 6 : Nematocytes of jellyfish, Fig. 7: Affected human leg, Fig.7: Affected human inside arm, Fig. 8: human entire arm until the palm back.
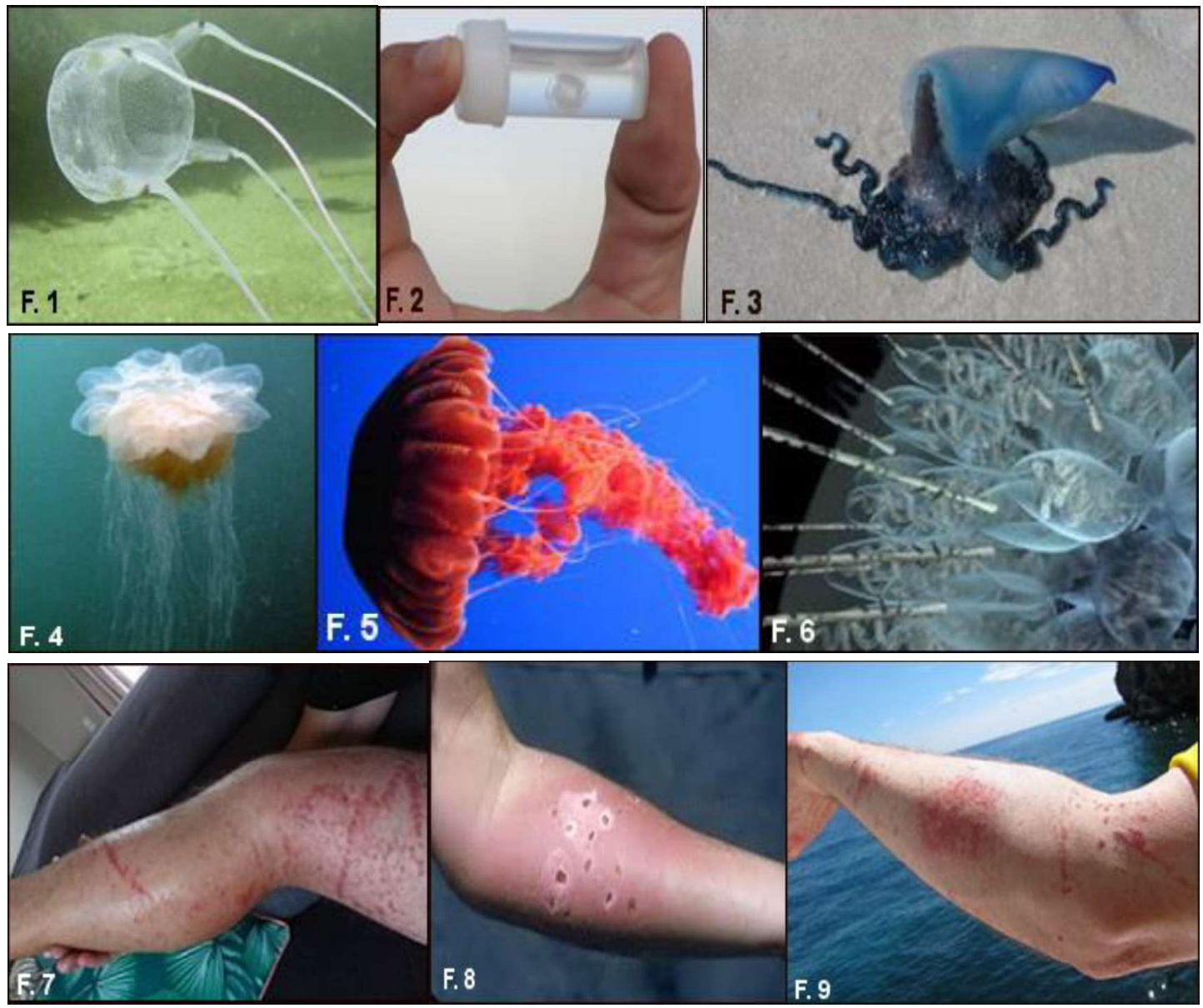